\title{
Outcomes of EUS-guided choledochoduodenostomy as primary drainage for distal biliary obstruction with covered self-expandable metallic stents
}

\section{다(1) $(9)$}

\author{
Authors \\ Yasumasa Niwa ${ }^{4}$, Shuji Terai ${ }^{2}$ \\ Institutions \\ 1 Department of Gastroenterology, Aichi Cancer Center \\ Hospital \\ 2 Department of Gastroenterology and Hepatology, \\ Graduate School of Medical and Dental Sciences, Niigata \\ University \\ 3 Department of Gastroenterological Surgery, Aichi \\ Cancer Center Hospital \\ 4 Department of Endoscopy, Aichi Cancer Center Hospital
}

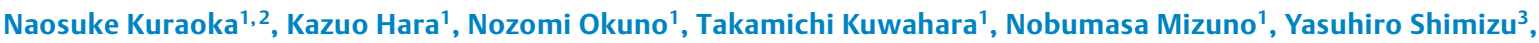

submitted 16.10.2019

accepted after revision 25.2.2020

Bibliography

DOI https://doi.org/10.1055/a-1161-8488 |

Endoscopy International Open 2020; 08: E861-E868

(c) Georg Thieme Verlag KG Stuttgart · New York

eISSN 2196-9736

Corresponding author

Kazuo Hara MD, PhD, Department of Gastroenterology,

Aichi Cancer Center, Kanokoden, Chikusa-ku, Nagoya,

Aichi, 464-8681, Japan

Fax: $+81-52-763-5233$

khara@aichi-cc.jp

\section{ABSTRACT}

Background and study aims Endoscopic ultrasonography-guided choledochoduodenostomy (EUS-CDS) is an alternative therapy for percutaneous transhepatic biliary drainage. Outcomes of EUS-CDS for distal biliary tract obstruction with a covered self-expandable metallic stent (SEMS) as a primary drainage technique are unclear because there are few relevant reports. This study aimed to determine outcomes in patients undergoing EUS-CDS using SEMS as the primary drainage technique for malignant distal biliary duct obstruction.

Patients and methods This retrospective study was conducted at Aichi Cancer Center Hospital, from January 2010 to July 2018, using data from our database.

Results EUS-CDS was performed as a primary drainage technique for 92 patients. The technical success rate was $92.8 \%$, and the clinical success rate was $91.6 \%$. The overall incidence of adverse events was $15.7 \%$. The median stent patency time for the EUS-CDS was 396 days. Nineteen patients required re-intervention because of cholangitis or jaundice.

Conclusion EUS-CDS as a primary drainage technique using SEMS has high technical and clinical success rates. It should be considered an effective drainage method with respect to long-term stent patency, low re-intervention rates, and absence of severe complications.

\section{Introduction}

Endoscopic ultrasonography-guided choledochoduodenostomy (EUS-CDS) is an alternative therapy for percutaneous biliary drainage (PTBD) for difficult cases of endoscopic retrograde cholangiopancreatography (ERCP) [1-3]. Compared to ERCP, EUS-CDS requires more advanced techniques and fatal incidents have been reported. However, incidence of post-procedure pancreatitis is low [4]. EUS-CDS for obstruction of the distal bile duct has been reported to have a high success rate, and there is little in-growth and over-growth of tumors after the procedure [4].
Endoscopic transpapillary stenting (ETS) using elf-expandable metallic stents (SEMS) for ERCP for distal bile duct obstruction with jaundice and cholangitis is currently common; however, pancreatitis may be observed as an adverse event (AE) [5]. Outcomes of EUS-CDS for distal biliary tract obstruction with covered SEMS as a primary drainage technique are currently unclear. Therefore, the purpose of this study was to measure outcomes of EUS-CDS as primary drainage and to determine its efficacy for primary drainage. 

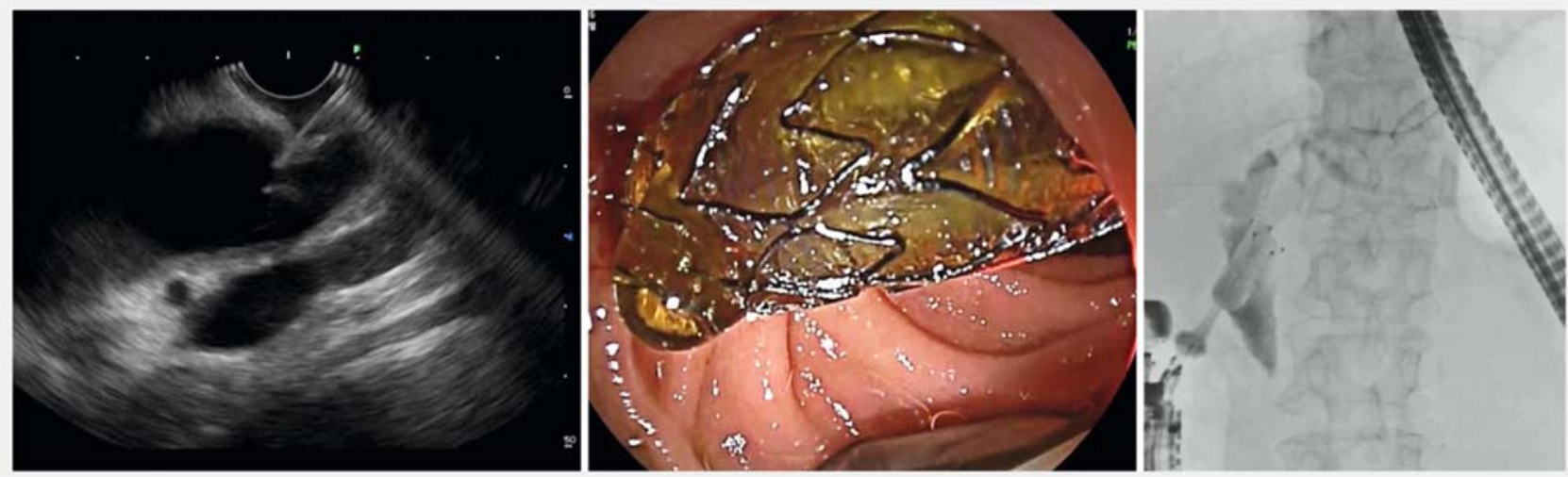

> Fig. 1 EUS-CDS procedures. EUD-CDS, endoscopic ultrasonography-guided choledochoduodenostomy

\section{Patients and methods}

\section{Study design}

This retrospective study was conducted at Aichi Cancer Center Hospital. Data were gathered from the hospital database on EUS-CDS with SEMS performed as a primary drainage technique for patients who had malignant distal biliary obstruction from January 2010 to July 2018.

All cases were limited to those in which PTBD or drainage using plastic stents placement had not been performed in advance. All patients were registered before procedures in our clinical database, and informed consent was obtained from all patients. Blood tests were performed the day after the procedures, and treatment efficacy was determined. Non-contrast computed tomography (CT) and plain abdominal $\mathrm{x}$-ray examinations were performed to confirm the position of the retention of SEMS.

The study was approved by the Institutional Review Board (IRB) of the Aichi Cancer Center Hospital (2019-1-135), and was performed in accordance with the Declaration of Helsinki [6].

In this study, 18 cases of EUS-CDS using SEMS that our center had previously reported were also examined [7].

\section{EUS-CDS procedures}

EUS-CDS were performed in all patients according to previously described standard procedures [8,9]. For all tests during EUSCDS, patients were sedated with midazolam and pethidine hydrochloride.

There were seven endoscopists in our hospital, and EUS-CDS was performed in all cases by three expert endoscopists who were skilled in EUS. Linear type EUS (GF-UCT 240, GF-UCT 260 or TGF-UC 260, Olympus medical systems, Tokyo, Japan, and EG-580UT, Fujifilm, Tokyo, Japan) was used to perform EUSCDS. EU-ME 2 (Olympus medical systems, Tokyo, Japan) and SU-1 (Fujifilm) were used as observation devices, and X-ray fluoroscopy was used while performing EUS-CDS.

For the puncture needle, a 19-G EUS-guided fine-needle aspiration (EUS-FNA) needle (Sono Tip Pro control, Medi-Globe,
$\mathrm{GmbH}$, Germany) was used. After bile juice aspiration, a 0.025-inch guidewire (Visiglide2, Olympus medical systems, Tokyo, Japan, or M-through, ASAHI INTECC, Japan) was placed in the bile duct. Following placement of the guidewire, fistula dilation was performed using a 6 Fr cautery dilator (Cysto-Gastro-Set, Endo-flex, Voerde, Germany). Next, a covered SEMS (Wallflex, Boston Scientific Japan, Japan, BONASTENT M-intraductal, Standard SciTech Inc, Seoul, South Korea or X-suit NIR Olympus medical systems, Tokyo, Japan) was inserted along the guidewire and advanced into the duodenal bulb from within the common bile duct (CBD) or common hepatic duct (CHD). Stent location was verified using $\mathrm{X}$-ray fluoroscopy and endoscopic imaging, and the procedures were completed. Finally, the stent location was changed to the anal side of the duodenum (॰ Fig. 1).

\section{Definitions}

Performance status (PS) referred to the performance status of the Eastern Cooperative Oncology Group [10]. Non-puncturable cases were defined as those where needle puncture could not be done after EUS observation was performed. Technical success was defined as the successful retention of SEMS was in the intended retention position. Clinical success was defined as improvement in cholangitis after deployment and/or a decrease in serum total bilirubin by $50 \%$ or a decrease to $3 \mathrm{~m} / \mathrm{dl}$ or less in postoperative blood tests [6].

Early AEs were defined as events that occurred within 30 days after the procedures. Late AEs were defined as events that occurred more than 30 days after the procedures. AEs were graded according to the American Society for Gastrointestinal Endoscopy (ASGE) lexicon's severity grading system [11]. Peritonitis was defined as abdominal pain, fever, and bile leakage on the first day after EUS-CDS. If CT showed findings such as liquid storage, the patient was diagnosed as bile leakage.

Procedure time was defined as the time from scope insertion to the reorientation of the stent. There were no prior EUS observations in any cases.

Stent patency day was defined as the period until reintervention was required due to cholangitis and jaundice. Cases that 


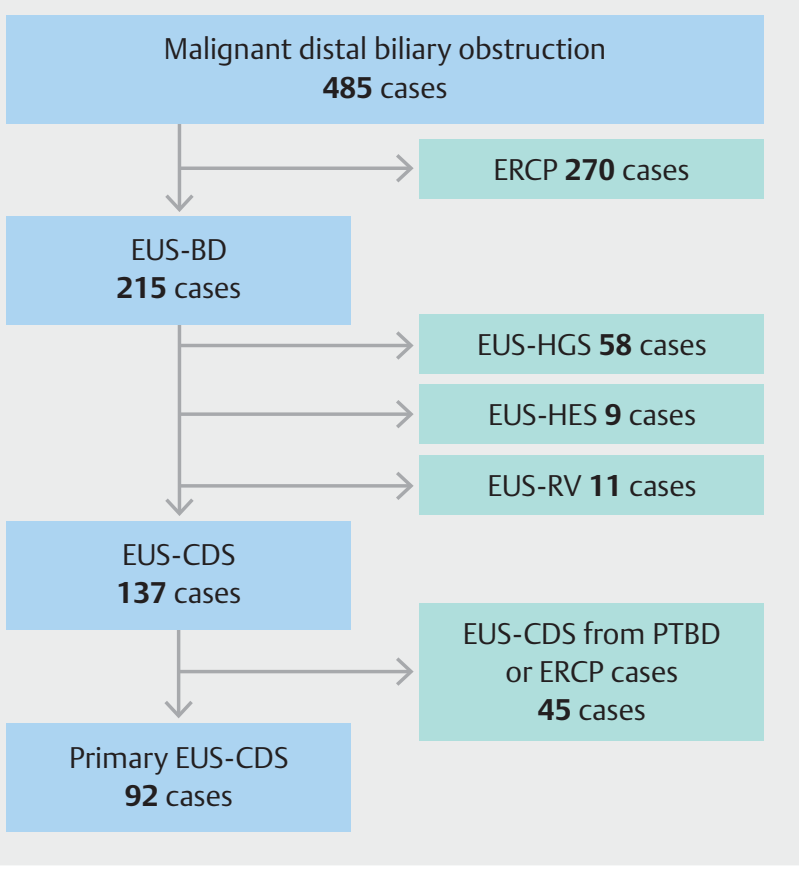

- Fig. 2 Cases of malignant distal biliary obstruction in the period.

resulted in death without causing stent occlusion were counted as patent.

Reintervention was defined when an endoscopic procedure or PTBD was performed because of cholangitis and/or jaundice.

\section{Statistical analysis}

Results are presented as the numerical value (\%), and continuous variables are presented as the median value [range]. Patients' characteristics were determined using intention-totreat analysis, whereas outcomes were determined using perprotocol analysis.

The median of the stent patency periods was calculated using the Kaplan-Meier method. Stent patency was compared using the log-rank test, and $P<.05$ was considered statistically significant. All statistical analyses were performed by using Statistical Product and Service Solutions (SPSS, IBM, Japan).

\section{Results}

From January 2010 to July 2018, there were 485 cases of malignant distal biliary obstruction. ERCP was performed in 270 cases either pre-operation or because of poor performance status. EUS-guided biliary drainage (BD) was performed in 215 cases. Of 215 cases, EUS-CDS was performed as a primary drainage in 92 patients ( $\triangleright$ Fig. 2 ).

In the EUS-CDS group, puncture was avoided in nine of 92 patients $(10.8 \%)$, and other drainage treatments were performed. After excluding these nine non-puncturable cases, 83 cases were examined with respect to success rate, AEs, and stent patency.
- Table 1 Patient characteristics.

\begin{tabular}{|l|c|}
\hline & $\mathbf{N}=\mathbf{9 2}$ \\
\hline Mean age (range) & $69(37-88)$ \\
\hline Sex, male/female & $55 / 37$ \\
\hline Diagnosis & \\
\hline - PDAC (\%) & $76(82.6)$ \\
\hline - Gallbladder carcinoma (\%) & $1(1.1)$ \\
\hline - Gastric cancer (\%) & $2(2.2)$ \\
\hline - Lung cancer (\%) & $4(4.3)$ \\
\hline - Esophageal cancer(\%) & $2(2.2)$ \\
\hline - Ampullary cancer (\%) & $4(4.3)$ \\
\hline - Cancer of unknown (\%) & $1(1.1)$ \\
\hline - Duodenal cancer & $1(1.1)$ \\
\hline - Small intestine cancer & $1(1.1)$ \\
\hline Performance status (PS), n & \\
\hline - $0 / 1 / 2 / 3$ & $75 / 14 / 2 / 1$ \\
\hline Duodenum stenosis (\%) & $16(17.4)$ \\
\hline Duodenal stenting before EUS-CDS (\%) & $13(14.1)$ \\
\hline Ascites (\%) & $33(35.9)$ \\
\hline Mild/moderate/massive, n/n/n & $23 / 8 / 2$ \\
\hline graphy-guided choledochoduodenostomy & \\
\hline
\end{tabular}

\section{Patient characteristics}

Patient characteristics are shown in $\downarrow$ Table 1 . A large proportion of patients had pancreatic ductal adenocarcinoma $(82.6 \%)$. Duodenal stenosis was observed in $17.4 \%$, and 13 underwent duodenal stenting before EUS-CDS was performed. There were 33 cases (35.9\%) with ascites ( $\bullet$ Table $\mathbf{1}$ ).

\section{Non-puncturable cases}

Puncture was avoided in nine of 92 patients (10.8\%), and other drainage treatments were performed. Six out of nine non-puncturable patients had pancreatic cancer. The reasons why puncture was avoided were as follows: one patient had deformity of duodenal bulb; two had cystic ducts on the puncture line; in three patients, the puncture site was directly below the hepatic hilum or near the hepatic hilum; in one patient, the tumor was on the line; in one patient there was puncture difficulty because of massive ascites; and in one patient, there was biliary tract bleeding from the tumor. Other biliary drainages options were selected for any of the cases. Biliary drainage was performed in seven non-puncturable cases by ETS. In one patient, it was performed using EUS-guided hepaticogastrostomy (HGS); and in one patient, it was performed using a EUS-guided rendezvous technique (RV). Drainage succeeded in all cases ( $\bullet$ Table 2 ). 
- Table2 Non-puncturable cases.

\begin{tabular}{|l|l|l|l|l|l|l|}
\hline Patient no. & Sex & Age & Diagnosis (cancer) & Reason for non-puncturable case & Ascites & Alternative drainage \\
\hline 1 & F & 64 & Unknown & Deformity of duodenal bulb & None \\
\hline 2 & F & 57 & Pancreas & Cystic duct on the puncture route & None & ETS \\
\hline 3 & M & 57 & Pancreas & posterior IHBD on the puncture route & None & ETS \\
\hline 4 & M & 68 & Lung & massive ascites & Massive & ETS \\
\hline 5 & M & 79 & Pancreas & The puncture site is the hepatic hilum & None & ETS \\
\hline 6 & F & 76 & Pancreas & Cystic duct on the puncture route & Moderate & EUS-HGS \\
\hline $\mathbf{7}$ & M & 59 & Stomach & Massive tumor on the puncture route & Mild & EUS-RV \\
\hline 9 & F & 59 & Pancreas & The puncture site is the hepatic hilum & Massive & ETS \\
\hline ETS, endoscopic transpapillary stenting; EUS-HGS, EUS-guided hepaticogastrostomy; EUS-RV, EUS-guided rendezvous technique & ETS \\
\hline
\end{tabular}

\section{Outcomes}

The technical success rate was $92.8 \%$, and the clinical success rate was $91.6 \%$. There were six cases in which the procedure was unsuccessful, and two cases had a plastic stent inserted because of the difficulty in placing the SEMS. In three cases, punctures were performed; these were near the hepatic hilum, and EUS-CDS was judged to be difficult. In one case, the procedure was performed until fistula dilatation but SEMS placement was difficult because the puncture position was near the hilum of the liver. That case was converted to EUS-HGS.

Indications for EUS-CDS and the number of technical successes are summarized in $>$ Fig. 3. Procedure time was 17.5 minutes (range 10-90) (> Table 3 ).

In 66 cases, EUS-CDS was performed by using a forwardviewing scope. The overall incidence of AEs was 15.7\%. Early AEs were found in $12.0 \%$. Among early AEs, there were five cases of peritonitis. There were two cases of double puncture of the duodenum as a characteristic incidental adverse event. A small number of cases of cholangitis, bleeding and cholecystitis were observed; however, there were no severe AEs recorded. Pancreatitis was not observed. Several cases of cholangitis due to stent dysfunction were recognized and required early re-intervention. Late adverse events were found in $3.6 \%$ of cases, including two cases of cholecystitis. One case of liver abscess was observed as a late AE ( $>$ Table 4$)$. All cases were relieved by conservative treatment.

\section{Stent patency}

Median patency for the EUS-CDS was 396 days (> Fig.4). The patency rate after 1 year was $58.9 \%$.

\section{Reintervention}

Nineteen cases needed reintervention because of cholangitis or jaundice. SEMS was removed or dislocated in eight cases. Stent migration was found in one case, and SEMS was removed in seven cases due to stent occlusion.

In these cases, contrast was injected, and fistula expansion was performed. Reintervention was performed from the EUS-

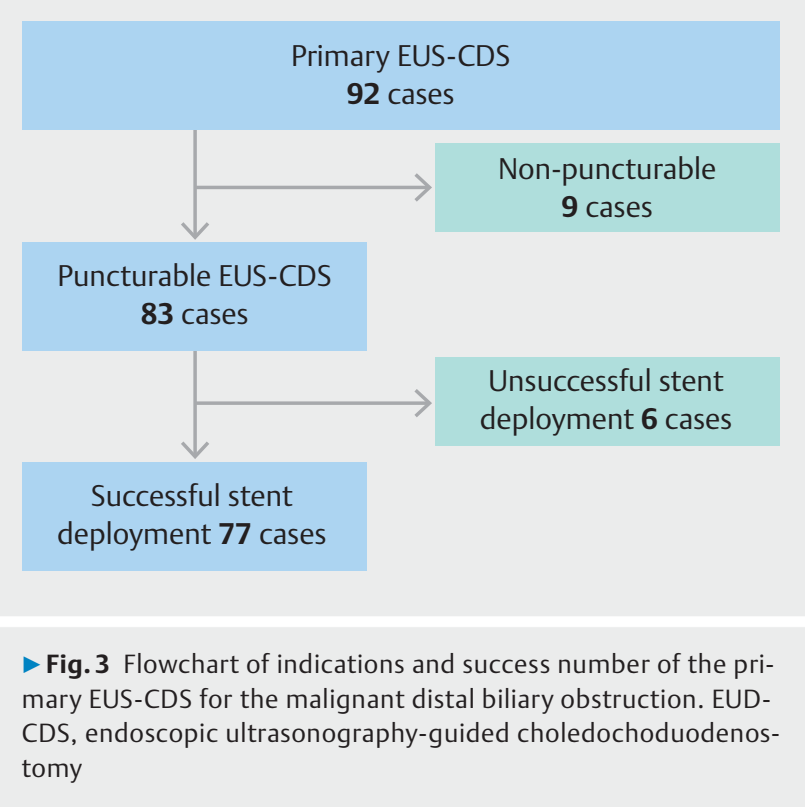

CDS fistula in 10 cases. In two cases, SEMS exchange was performed, and in two others, stent cleaning was performed. There were four cases requiring an additional stent, and two where the stent position was changed. At the time of reintervention, only one case required a new drainage route. EUSHGS was performed in that case ( $\mathbf{F i g} . \mathbf{5}$ ).

\section{EUS-CDS with duodenal stenting}

Duodenal stenting prior to EUS-CDS was performed in 13 cases. In three cases, the duodenal stenting was performed after EUSCDS. Fourteen cases among them were for pancreatic cancer, one for gastric cancer and one for duodenal cancer. Puncture was not possible in one case, whereas SEMS deployment could not be done in two cases. The technical success rate was $86.7 \%$, and the clinical success rate was $100 \%$. Regarding early AEs, peritonitis occurred in one case ( $\downarrow$ Table 5$)$. 
- Table 3 Outcomes of procedures.

\begin{tabular}{|l|l|}
\hline & EUS-CDS \\
\hline & $\mathbf{( N = 9 2 )}$ \\
\hline Non-puncturable cases, $\mathrm{n} / \mathrm{N}(\%)$ & $9 / 92(9.8)$ \\
\hline Technical success rate, $\mathrm{n} / \mathrm{N}(\%)$ & $77 / 83(92.8)$ \\
\hline Clinical success rate (\%), $\mathrm{n} / \mathrm{N}(\%)$ & $76 / 83(91.6)$ \\
\hline Procedure time, median min(range) & $17.5(10-90)$ \\
\hline Scope, OV/FV, $\mathrm{n} / \mathrm{n}$ & $26 / 66$ \\
\hline Stent type, laser cut/braided/10mm-LAMS, n/n/n & $30 / 46 / 1$ \\
\hline Stent diameter, $10 \mathrm{~mm} / 12 \mathrm{~mm}, \mathrm{n} / \mathrm{n}$ & $71 / 6$ \\
\hline Overall adverse event, $\mathrm{n} / \mathrm{n}(\%)$ & $13 / 83(15.7)$ \\
\hline $\begin{array}{l}\text { OV, oblique viewing scope; } \mathrm{FV}, \text { forward viewing scope; LAMS, lumen-ap- } \\
\text { posing metallic stent }\end{array}$ \\
\hline
\end{tabular}

- Table 4 Details on adverse events.

\begin{tabular}{|l|l|}
\hline & EUS-CDS \\
\hline & $\mathbf{( n = 8 3 )}$ \\
\hline Early adverse event, $\mathrm{n}(\%)$ & $10(12.0)$ \\
\hline Cholangitis, $\mathrm{n}(\%)$ & $5(6.0)$ \\
\hline - Mild/moderate & $4 / 1$ \\
\hline Peritonitis, mild $\mathrm{n}(\%)$ & $2(2.4)$ \\
\hline - Mild/moderate & $2 / 0$ \\
\hline Bleeding, n (\%) & $1(1.2)$ \\
\hline - Mild/moderate & $1 / 0$ \\
\hline Double penetration of duodenum, $\mathrm{n}(\%)$ & $2(2.4)$ \\
\hline - Mild/moderate & $2 / 0$ \\
\hline Late adverse event, $\mathrm{n}(\%)$ & $3(3.6)$ \\
\hline Cholecystitis, $\mathrm{n}(\%)$ & $2(2.4)$ \\
\hline - Mild/moderate & $2 / 0$ \\
\hline Liver abscess, $\mathrm{n}$ (\%) & $1(1.2)$ \\
\hline - Mild/moderate & $1 / 1$ \\
\hline EUS-CDS, endoscopic ultrasonography-guided choledochoduodenostomy & \\
\hline
\end{tabular}

Median stent patency time for EUS-CDS when duodenal stenting was performed was 119 days, the median patency period for patients with prior duodenal stent placement was 119 days, and the median stent patency of patients without duodenal stents was 396 days. The median stent patency period in the cases without duodenal stent insertion was longer than in the case of prior placement of the duodenal stent; however, no significant difference was observed ( $\triangleright$ Fig.6).

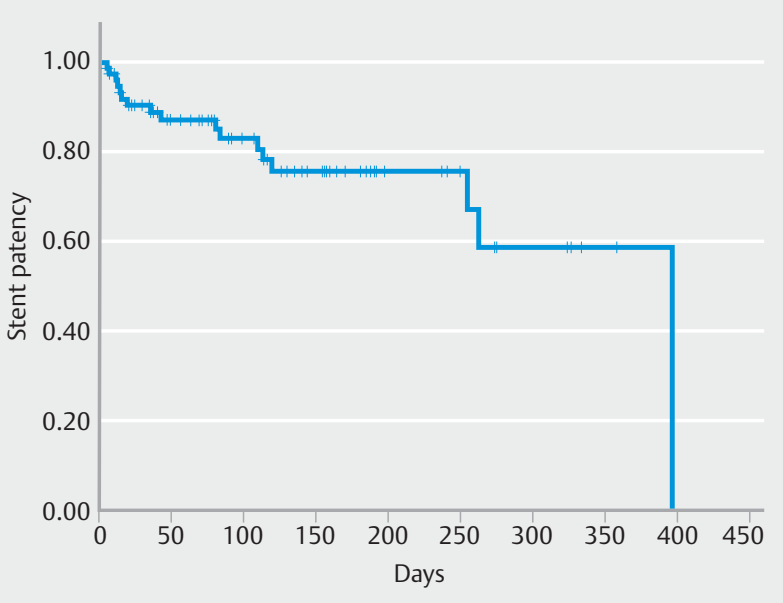

- Fig. 4 Stent patency for EUS-CDS. Median stent patency time was 396 days, and the patency rate after 1 year was 58.9\%. EUD-CDS, endoscopic ultrasonography-guided choledochoduodenostomy

\begin{tabular}{|c|c|c|}
\hline \multicolumn{3}{|c|}{$\begin{array}{l}\text { SEMS deployment for EUS-CDS } \\
77 \text { procedures }\end{array}$} \\
\hline \multirow[b]{2}{*}{$\begin{array}{c}\text { Re-intervention } \\
19 \text { procedures [24.5\%] }\end{array}$} & & \\
\hline & $\rightarrow$ & $\begin{array}{c}\text { Stent remove or } \\
\text { dislocation } \\
\mathrm{n}=\mathbf{8}\end{array}$ \\
\hline \multirow{2}{*}{$\begin{array}{l}\text { Re-intervention from } \\
\text { EUS-CDS fistula } \\
\mathbf{1 0} \text { procedures }\end{array}$} & & $\downarrow$ \\
\hline & & $\begin{array}{l}\text { Re-intervention } \\
\text { from another route } \\
\mathbf{1} \text { procedure }\end{array}$ \\
\hline$\downarrow$ & & $\downarrow$ \\
\hline $\begin{array}{l}\text { SEMS exchange } n=2 \\
\text { Stent cleaning } n=2 \\
\text { Additional stent } n=4 \\
\text { Position change } n=2\end{array}$ & & $\begin{array}{l}\text { EUS-HGS } \\
\qquad n=1\end{array}$ \\
\hline \multicolumn{3}{|c|}{$n=19$} \\
\hline Technical success rate & $100 \%$ & \\
\hline Clinical success rate & $100 \%$ & \\
\hline
\end{tabular}

- Fig. 5 Outcomes of reintervention. Nineteen cases required re-intervention because of cholangitis or jaundice. The technical/ clinical success rate was $100 \%$.

\section{Discussion}

We examined 92 cases in which EUS-CDS was performed as the primary drainage technique. In nine cases, it was judged by EUS observation that EUS-CDS could not be performed.

The technical success rate of 83 cases except for nine was high $(92.8 \%)$, and that was similar to the previously reported 
- Table 5 Patient characteristics and outcomes of cases with EUSCDS with duodenal stenting.

\begin{tabular}{|l|c|}
\hline & $\mathbf{n}=\mathbf{1 6}$ \\
\hline Mean age (range) & $69(39-80)$ \\
\hline Sex, male (\%) & $11(68.8)$ \\
\hline Duodenal stenting before EUS-CDS & $13(81.3)$ \\
\hline Diagnosis & $14(87.5)$ \\
\hline - PDAC (\%) & $1(6.3)$ \\
\hline - Gastric cancer (\%) & $1(6.3)$ \\
\hline - Duodenal cancer (\%) & $1(6.3)$ \\
\hline - Non-puncturable case, $n$ (\%) & $13 / 15(86.7)$ \\
\hline - Technical success rate, n/n (\%) & $13 / 13(100)$ \\
\hline - Clinical success rate, (\%) & $1 / 16(6.3)$ \\
\hline - Adverse event rate, $n / n$ (\%) & \\
\hline $\begin{array}{l}\text { EUS-CDS, endoscopic ultrasonography-guided } \\
\text { choledochoduodenostomy; PDAC, pancreatic ductal adenocarcinoma }\end{array}$
\end{tabular}

success rate of $87 \%$ to $100 \%$. The clinical success rate was also high (91.6\%), comparable to previously reported success rates of $77 \%$ to $100 \%[3,4,7,12-17]$. The incidence of AEs was $15.7 \%$, similar to the previously reported AEs of $7 \%$ to $23 \%$; however, incidence of peritonitis was lower than that reported in the previous reports [3,12-17]. There were only two cases of postoperative cholecystitis, and the dominant risk factor could not be determined.

There were two cases of cholecystitis: a case of gallbladder cancer infiltrating the gallbladder duct and a case of SEMS obstruction due to SEMS.

In a case of gallbladder cancer invading the gallbladder duct, gallbladder puncture was performed after EUS-CDS; nevertheless, cholecystitis developed. Gallbladder duct obstruction due to a stent was a case that developed cholecystitis as a late complication and performed gallbladder puncture.

Median stent patency was 396 days. Although this was similar to that reported in a previous study, it was considered a sufficient patency period because many pancreatic cancer cases were seen during this period [18]. As long as a metal stent is made of metal, the stent patency period is unlikely to be significantly longer.

Recent randomized controlled trials reported non-inferiority of EUS-BD for malignant distal biliary strictures. All reports showed high success rates (90.9\%-100\%), and no serious incidents were observed, as in the current report. Stent patency was comparable to that of ERCP-BD [19-21]. The technical and clinical success rates were high and the rate of AEs was low in the duodenal stent combined cases. Furthermore, the technical and clinical success rates were high and the rate of the AEs was low in the duodenal stent combined cases.

At the time of reintervention, only one case that underwent EUS-HGS needed additional drainage. Fistula formation occurs because of use of SEMS for EUS-CDS, necessitating reinterven-

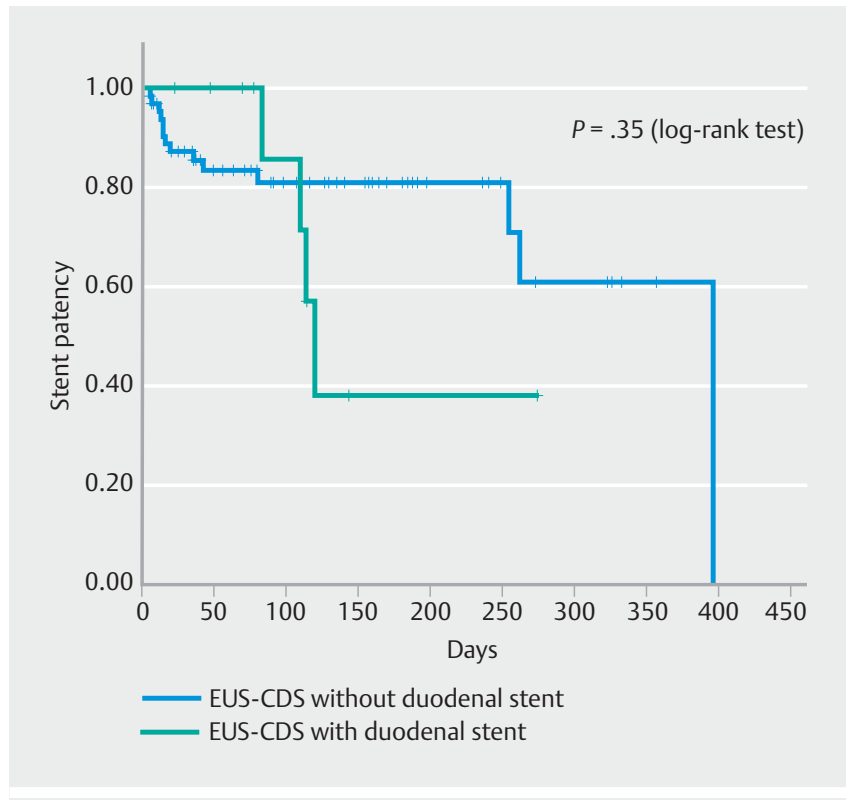

- Fig. 6 Stent patency of EUS-CDS with/without duodenal stenting. Median patency time for EUS-CDS without duodenal stenting was 396 days, and median patency time for EUS-CDS with duodenal stenting was 119 days. There was no significant difference between the two groups. EUD-CDS, endoscopic ultrasonographyguided choledochoduodenostomy

tion. Of 19 cases, there were 17 cases due to sludge, one case of fistula closure after the departure from the stent, and one case of reintervention due to tumor progression. EUS-HGS was performed for tumor invasion. Compared to ERCP, tumor infiltration occurred less often and sludge occlusion was more likely.

Although there was no significant difference in the duodenal stent combination case, the patency period was short. We believe that it was influenced by the increase in the accumulation of sludge and debris by the duodenal stent.

Reintervention was mostly due to sludge and debris, and only one case was due to tumor invasion. Tumor invasion may occur less often than in ERCP-BD.

The usefulness of EUS-CDS was reported first by Wiersema et al. [1] who reported two cases of EUS-guided cholangiopancreatography for ERCP failure in 1996. Since then, EUS-CDS has been reported to be a useful alternative treatment of PTBD for ERCP failure cases [22-25]. In contrast, there are few reports of EUS-CDS for malignant distal biliary obstruction as the primary drainage technique.

In this study, EUS-CDS as primary drainage for malignant distal biliary obstruction was determined to be effective based on its high success rate and lack of fatal incidents. It was possible to perform the procedure without problems in cases of duodenal stenosis, which makes ERCP difficult. There have been few reports in which the indications for EUS-CDS have been examined in detail; however, in the current study, indications were determined by performing EUS observation before the implementation of EUS-CDS.

Nine non-puncturable cases were recognized, in which the inclusion was found on the puncture route. There were many 
cases in which it was difficult to puncture due to bile duct or tumor.

Although there are few reports on long-term outcomes with performing a reintervention, reintervention was possible via EUS-CDS fistula in all cases in the current study. As mentioned above, only one case required a new drainage route in reintervention, and reintervention from the fistula was considered to be possible without problems. Because SEMS was used for EUS-CDS, fistulas formed easily and re-intervention was also possible.

EUS-CDS requires advanced techniques although it has a high success rate. The reason may be that there is no dedicated device and existing biliary stent devices are used. In recent years, EUS-CDS using lumen-apposing metal stents, a new type of stent, has also been reported [26]. Using this new type of device, an increase in success rate and a decrease in adverse events may be expected.

This study has some limitations. This was a single-institution retrospective study. The practicing physician in this study was an expert; therefore, our results may not be generalizable. To establish EUS-CDS as a standard treatment, large-scale clinical studies should be considered in the future.

\section{Conclusion}

EUS-CDS using SEMS as primary drainage is appropriate as a primary drainage considering the high technical success rate, low accident rate, and long stent patency period. Even in cases of duodenal stenosis where ERCP is considered difficult, a high success rate is seen, and EUS-CDS is considered an effective method. Sufficient stent patency is obtained, and EUS-CDS was not associated with severe adverse events such as pancreatitis. EUS-CDS as the primary drainage should be considered useful.

\section{Competing interests}

The authors declare that they have no conflict of interest.

\section{References}

[1] Wiersema MJ, Sandusky D, Carr R et al. Endosonography-guided cholangiopancreatography. Gastrointest Endosc 1996; 43: 102-106

[2] Mallery S, Matlock J, Freeman ML. EUS-guided rendezvous drainage of obstructed biliary and pancreatic ducts: Report of 6 cases. Gastrointest Endosc 2004; 59: 100-107

[3] Kawakubo K, Isayama H, Kato H et al. Multicenter retrospective study of endoscopic ultrasound-guided biliary drainage for malignant biliary obstruction in Japan. J Hepatobiliary Pancreat Sci 2014; 21: 328334

[4] Hara K, Yamao K, Niwa Y et al. Prospective clinical study of EUS-guided choledochoduodenostomy for malignant lower biliary tract obstruction. Am J Gastroenterol 2011; 106: 1239-1245

[5] Kawakubo K, Isayama H, Nakai Y et al. Risk factors for pancreatitis following transpapillary self-expandable metal stent placement. Surg Endosc 2012; 26: 771-776
[6] World Medical Association Declaration of Helsinki. ethical principles for medical research involving human subjects. JAMA 2013; 310: 2191-2194

[7] Hara K, Yamao K, Hijioka S et al. Prospective clinical study of endoscopic ultrasound-guided choledochoduodenostomy with direct metallic stent placement using a forward-viewing echoendoscope. Endoscopy 2013; 45: 392-396

[8] Hara K, Yamao K, Mizuno N et al. Endoscopic ultrasonography-guided biliary drainage: Who, when, which, and how? World J Gastroenterol 2016; 22: 1297-1303

[9] Ogura T, Higuchi K. Technical tips of endoscopic ultrasound-guided choledochoduodenostomy. World J Gastroenterol 2015; 21: 820-828

[10] Oken MM, Creech R, Tormey DC et al. Toxicity and response criteria of the Eastern Cooperative Oncology Group. Am J Clin Oncol 1982; 5: 649-655

[11] Cotton PB, Eisen GM, Aabakken L et al. A lexicon for endoscopic adverse events: report of an ASGE workshop. Gastrointest Endosc 2010; 71: 446-454

[12] Song T], Hyun YS, Lee SS et al. Endoscopic ultrasound-guided choledochoduodenostomies with fully covered self-expandable metallic stents. World J Gastroenterol 2012; 18: 4435-4440

[13] Poincloux L, Rouquette O, Buc E et al. Endoscopic ultrasound-guided biliary drainage after failed ERCP: cumulative experience of 101 procedures at a single center. Endoscopy 2015; 47: 794-801

[14] Kunda R, Perez-Miranda M, Will U et al. EUS-guided choledochoduodenostomy for malignant distal biliary obstruction using a lumen-apposing fully covered metal stent after failed ERCP. Surg Endosc 2016; 30: 5002-5008

[15] Khashab MA, Messallam AA, Penas I et al. International multicenter comparative trial of transluminal EUS-guided biliary drainage via hepatogastrostomy vs. choledochoduodenostomy approaches. Endosc Int Open 2016; 4: E175-E181

[16] Dhir V, Itoi T, Khashab MA et al. Multicenter comparative evaluation of endoscopic placement of expandable metal stents for malignant distal common bile duct obstruction by ERCP or EUS-guided approach. Gastrointest Endosc 2015; 81: 913-923

[17] Rai P, Lokesh CR, Goel A et al. Endoscopic ultrasound-guided choledochoduodenostomy using partially-covered self-expandable metal stent in patients with malignant distal biliary obstruction and unsuccessful ERCP. Endosc Int Open 2018; 6: E67-E72

[18] Nakai Y, Isayama H, Kawakami H et al. Prospective multicenter study of primary EUS-guided choledochoduodenostomy using a covered metal stent. Endosc Ultrasound 2019; 8: 111-117

[19] Bang JY, Navaneethan U, Hassan M et al. Stent placement by EUS or ERCP for primary biliary decompression in pancreatic cancer: a randomized trial (with videos). Gastrointest Endosc 2018; 88: 9-17

[20] Paik WH, Lee TH, Park DH et al. EUS-guided biliary drainage versus ERCP for the primary palliation of malignant biliary obstruction: a multicenter randomized clinical trial. Am J Gastroenterol 2018; 113: 987-997

[21] Park JK, Woo SW, Noh DH et al. Efficacy of EUS-guided and ERCPguided biliary drainage for malignant biliary obstruction: prospective randomized controlled study. Gastrointest Endosc 2018; 88: 277-282

[22] Yamao K, Sawaki A, Takahashi K et al. EUS-guided choledochoduodenostomy for palliative biliary drainage in case of papillary obstruction: report of 2 cases. Gastrointest Endosc 2006; 64: 663-667

[23] Giovannini M, Moutardier V, Pesenti C et al. Endoscopic ultrasoundguided bilioduodenal anastomosis: a new technique for biliary drainage. Endoscopy 2001; 33: 898-900

[24] Burmester E, Niehaus ], Leineweber T et al. EUS-cholangio-drainage of the bile duct: report of 4 cases. Gastrointest Endosc 2003; 57: 246251 
[25] Yamao K, Bhatia V, Mizuno M et al. EUS-guided choledochoduodenostomy for palliative biliary drainage in patients with malignant biliary obstruction: results of long-term follow-up. Endoscopy 2008; 40: $340-342$
[26] Tsuchiya T, Bun Teoh AY, Itoi T et al. Long-term outcomes of EUSguided choledochoduodenostomy using a lumen-apposing metal stent for malignant distal biliary obstruction: a prospective multicenter study. Gastrointest Endosc 2018; 87: 1138-1146 